\title{
Analysis of health education utilization of migrants in Beijing using Anderson health service utilization model
}

\author{
Shuang Shao \\ Capital Medical university \\ Huirong Zhang \\ Beijing Geriatric hospital \\ Jingyuan Xuxiao \\ Capital Medical University \\ Xiaolei Chen \\ Capital Medical University \\ Yali Zhao \\ Capital Medical University \\ Juan Du ( $\nabla$ cuckoo@ccmu.edu.cn )
}

Research article

Keywords: Migrant, Health education utilization, Determinant factor, Anderson health service utilization model

Posted Date: September 19th, 2019

DOI: https://doi.org/10.21203/rs.2.14666/v1

License: (c) (1) This work is licensed under a Creative Commons Attribution 4.0 International License. Read Full License 


\section{Abstract}

Background: Domestic migration is considered as a challenge for China. Migrants are vulnerable to certain risks and diseases due to encounter several obstacles to accessing preventive care services. This research sought to unveil and explore the determinant factors associated with health education utilization as one important aspect of basic public health services for migrants in Beijing of China.

Methods: A sample of 863 inter-provincial migrants who were 18 years old and above was chosen by three-stage stratified cluster sampling method in 2016 urban-rural connection districts of Beijing. A structured questionnaire survey was conducted via face-to-face interviews. Anderson health service utilization model was used to demonstrate the effects of the explanatory variables on health education seeking behavior from predisposing, enabling, health behavior and need variables.

Results: The study revealed that $60.4 \%$ migrants desired to receive health education, while only $34.5 \%$ of them received in the past year. Many migrants desired to access various types of health education information from the internet. Chi-square independence test shows that age, "Hukou" registration system, marital status, education level, plan to reside for a long time in Beijing, have at least one child in Beijing, employment status, housing source, average working time daily, do exercises, acquire health knowledge, smoking, self-evaluation general health status are the major determinants affecting migrants to receive whole health education. The binary logistic regression indicates that the migrants with younger, high education level, have at least one child in Beijing, do exercises and self-evaluated good health status were more likely to receive whole health education. The results also show that average working time daily of enabling variables and do exercise of health behavior variables were the strong and consistent determinants of three types of health education utilization, including communicable, non-communicable and occupational diseases.

Conclusion: There were certain gaps between the needs and utilization in health education. More attention should be given to the migrants with heavy workload and low education level. Relevant policies and feasible measures, including health providing health information by multiple channels, should be vigorously implemented to ensure easy and equitable access to health education for migrants.

\section{Background}

Domestic migration is considered a major social, political and public health system challenge for the urban cities of China. Migrants refer to individuals who move from the place where they live to other areas of the country without possessing the local "Hukou" (residence registration certificates), including interprovince or rural-to-urban migrants population. In the past few decades, the number of migrants population in China has being increasing dramatically, reaching to 245 million and constituted $18 \%$ of the total population in 2016 [1]. Although migrants are needed for socioeconomic development and urban construction in major cities, they often encounter several obstacles to accessing public services because of their distinguishing characteristics irregular status (e.g. low paid wages, low education level, poor living condition, and insufficiently protected working environment) and economic and social marginalization (many public policies and social welfare programs were implemented based on a rigid "Hukou" system, serving as a domestic passport) [2, 3]. They suffer certain unnoticed health risks that can wear off their health awareness and make them vulnerable to health problems, such as communicable disease (CD), chronic non-communicable disease (NCD) and occupational disease, and also relatively easy to ignore their own health status [4,5].

The real weakness of China's public health system had been exposed after the outbreak and epidemic of Severe Acute Respiratory Syndrome (SARS) in 2003 [6]. The Chinese government realized that the health status and health awareness of public population particular migrants, had a considerable impact on Chinese social stability and public health [7], and the fragmentary public health prevention and intervention systems should be re-established to control the spread of diseases and reduce the waste of medical resources [8]. As an important part of promoting the gradual equalization of basic public health services, and important issue for Chinese healthcare reform, the program of National Basic Public Health Services was implemented in 2009 and provided the services to residents [9]. The basic public health services are free and voluntary public services provided for permanent residents by primary health care institutions, including village clinics, township health centers, and community health service centers (stations), focusing on preventing and controlling diseases by public health intervention measures. At present, the basic public health services included fourteen basic items (e.g., the establishment of health records, health education, vaccine inoculation, children and maternal health management, tuberculosis and hypertension management). The government also raised the subsidy from 15 Renminbi (RMB) per capita in 2009, 25 RMB in 2011 to 45 RMB in 2016 for financing this project.

It cannot be denied that the rate of basic public health service utilization has increased rapidly among community permanent residents. The effectiveness of services also has improved obviously (e.g., save a significant number of lives, reduce suffering and ill health) with the strengthening of national support [10]. As far as the basic public health service is concerned, the migrants are difficult to enter the basic public health service network due to most of them are flow frequently. There is still an imbalance of basic public health services utilization between the local and migrant population, such as migrants have lower health awareness[11], high rate of spread of communicable diseases [12, 13], compared with local residents. At present, the trend of migration has changed from "temporary residence" and "migrant alone" to "long-term residence" and "migration with family members" in the last decade [14]. With the change of migration model, diversified requirements of public health services should to be satisfied for migrants. If the demands and utilization of basic public health services for them are not guaranteed, there will be a series of social problems as well as a potential threat to the health of the local residents. The Health Sector Reform formulated a series of strategies to "build up a strong basic public health service network." to promote the equalization of basic public health services. Since 2014, the National Health and Family Planning Commission (renamed National Health Commission of the People's Republic of China from 2017) launched trials work on the basic public health services equalization for improving the health of the migrant population in 40 cities across the country [15]. Put simply, providing accessible and good-quality basic public health services for migrants is an important issue.

As one item of the services in the basic public health services, health education intervention and materials has proven to be an effective strategy for strengthening the aspects of health knowledge, awareness and positive health behaviors. Furthermore, health education is essential to improving CDs and NCDs prevention, control, and treatment for everyone at every level and to the target group, particularly in the marginalized and migrant populations [16-18]. It 
is also likely to be instrumental in effectively addressing growing health care costs and in preventing or mitigating the negative effects of migration on health systems and societies. While, previous study found that compare to a relatively high use of medical care, preventive care was used less frequently among migrants [19]. With an increasing sense of health among the general public including migrants, current contents and traditional face-to-face education of health information ignores the actual utilization situation and true demands of the general public [20]. In order to implement successful policies to target social and health inequalities among the migrant populations, policy makers need to understand what barriers migrants face to integrate, and also need to identify and address their health demands.

As the political, economic and cultural center, as well as the pilot city of China, Beijing attracts tens of thousands of migrants from all over the country every year [21]. Systematic research on health education utilization behavior and influence factors of migrants is far from sufficient. Meanwhile the research results are crucial to disease prevention and health promotion for the migrants in China. We aim to (1) evaluate differences between utilization and demands of health education; (2) put forth the potential major determinant factors of health education utilization behaviors in different sociodemographic, health behavior and health outcome setting for migrants in Beijing by using the simplified Anderson health service utilization model. The comparisons and inferences could help us figure out the obstacles to seek health education for migrants, and take targeted interventions measures to improve their health literacy, control disease and promote health status.

\section{Analytic Framework}

As a well-validated theoretical framework, Andersen health service utilization model is to predict determinants of health services utilization, taking into consideration both individual and societal determinants [22]. According to the model, health education utilization is determined by three dynamics: predisposing, enabling, and need variances (PEN). Social demographic characteristics include sex, age, race, can be divided into predisposing factors, which increase one's needs for health education services. For example, a person who believes health education services are effective measures for preventing disease is more likely to seek health education. Enabling factors are comprised of individual, family and community resources support, that can facilitate or impede the use of health education services. Need factors represent both actual need and self-perceived for health education services. In our study, health behavior variances as one type of the important dynamics parameters were added to evaluate the predictions of a new model. In our study, a feedback loop was used to illustrate the relationship between health education behavior (seek health education, and not seek health education) and other aspects. (See figure 1)

\section{Methods}

\section{Ethics Statement}

The study was undertaken as a part of Beijing Philosophy and Social Science Planning Project, which is a population-based cross sectional survey on risk factors of health status for migrants. It was approved by the Ethical Committee of Capital Medical University, Beijing, China. Data were collected from a 2016 cross-sectional survey in urban-rural connection districts of Beijing. Considering the parents or guardians are the main decision-makers in the attitudes and decisions about public health services for children, thus those under 18 years of age were not included in this study. Written informed consent was obtained from each participant involved in this study. All participants' information will be anonymized and kept confidential.

\section{Data acquisition and study population}

A fieldwork survey of Beijing Urban-Rural Connection Migrants Population Public Health Service Utilization was performed from June to November 2016. All respondents were at least 18 years old, including interprovincial migrants resided or worked in the sampling regions(for no less than six months). Migrants who mentally unfit to respond and those visited to Beijing were excluded. The structural questionnaire includes four parts of variances as follows: predisposing factors (sociodemographic characteristics), enabling factors (individual/family resources), need factors (general health status), health behavior factors (health promotion behaviors and health hazard behaviors) and health education seeking behavior (receiving health education or not). Qualityassurance measures implemented for this survey consists of evaluation of the questionnaire, training for the investigators and supervision of the fieldwork to monitor the survey procedure. It was reviewed, edited, and validated by experts from health administration and community health service institutions (CHSIs) before it was implemented. A trial survey covering 50 persons was implemented between June 6 to 11, 2016 to improve the comprehensibility of the questionnaire and the fieldwork procedures. The Cronbach's alpha coefficient calculated for internal consistency of the questionnaire was equal to 0.85 and considered acceptable.

The migrants of Beijing dwell mainly in 5 (Chaoyang, Haidian, Fengtai, Daxing, Changping districts) out of 16 districts. Five districts were divided into two types of region based on the number of migrants, including the region with more than 1 million migrants (Chaoyang, Haidian districts) and the region with 0.5 to 1 million migrants (Fengtai, Daxing, Changping districts). A sample of 1,000 migrants was chosen from two of the five districts in Beijing by using stratified three-stage cluster random sampling, as follows: In the first stage, one district was chosen from the fist region (Haidian district), and another district was chosen from the secondary region (Fengtai district). In the second stage, two streets according to the population size and social economic condition from each sampled districts were chosen respectively. Finally, the total number of 1,000 migrants was recruited and investigated from four streets. The migrants was sampled in Haidian (500), Fengtai (500) respectively. Data were collected via face-to-face interview. Finally, a total of 863 respondents were analyzed after excluding the data having missing information on any of variables in the research. Double entry and validation was adopted for all data using EpiData software (Version 3.1, EpiData Association, Odense, Denmark). Discrepancies which compared and analyzed from the two databases, would be clarified by reviewing the original data source.

\section{Statistical analysis}


A person was the unit of seeking health education at least once in the past year, rather than total number of times health education received. Chisquare independence test was used to analyzed the differences in the categorical variables. Odds Ratios (ORs) and their $95 \%$ confidence intervals (Cls) were calculated using binary logistic regression analysis. In the first step, descriptive statistics and chi-square independence test were calculated, stratified by the categories of health education utilization (receive and non receive health education). In the second step, a binary logistic regression analysis was performed to predict the potential major determinant factors of affecting health education utilization for migrants, controlling for possible confounding variables. The full model consist of all of the predisposing, enabling, health-related behaviors and the need factors were entered into the model. The full list of independent variables is summarized in the table 1. All statistical analyses were performed using IBM Statistical Package for Social Science version 20.0 (SPSS Inc., Chicago IL, US) and all the tests are two sided. The significance level for all analyses was set at $P<0.05$.

\section{Results}

A total of 863 inter-provincial migrants (males 383; females 480) in Beijing above 18 years old were investigated. The age of migrants is from 18 to 76 years old, and the average was $36.6 \pm 11.2$ years old.

Utilization of health education in the past year

Table 2 shows that $60.4 \%$ migrants desired to received any one type of health education, while only $34.5 \%$ of them received. The top five types of health education received by migrants were "child healthcare" (15.8\%), "occupational disease prevention and therapy" (15.1\%), "antenatal, prenatal and postpartum healthcare" (14.9\%), "communicable disease prevention and therapy" (12.4\%), and "non-communicable disease prevention and therapy" (11.1\%). While the top five types of health education demanded to receive by migrants were "non-communicable disease prevention and therapy" (61.2\%), "communicable disease prevention and therapy" (48.9\%), "aged healthcare" (47.4\%), "child healthcare" (46.8\%), and "adolescent healthcare" (38.0\%).

Additionally, the top three pathways which migrants want to acquire health information was from television broadcasting (62.8\%), internet (web page and WeChat) (58.2\%), and professionals and health managers (37.4\%).

Descriptive statistics and chi-square independence test were used to describe the information and analyze the influence factors of health education utilization by sociodemographic factors. Chi-square independence test showed that age, "Hukou"registration system, marital status, education level, plan to reside for a long time in Beijing, have at least one child in Beijing, employment status, housing source, average working time daily, do exercises, acquire health knowledge, smoking, self-evaluation general health status are the major determinants affecting migrants to receive health education. (See table 3 )

Gender, "Hukou" registration system, education level, plan to reside for a long time in Beijing, have at least one child in Beijing, employment status, housing source, average working time daily, do exercises, acquire health knowledge are the major determinants affecting migrants to receive communicable disease health education. "Hukou"registration system, housing source, average working time daily, do exercises are the major determinants affecting migrants to receive non-communicable disease health education. Age, "Hukou"registration system, marital status, education level, plan to reside for a long time in Beijing, have at least one child in Beijing, employment status, average working time daily, do exercises, acquire health knowledge, smoking, are the major determinants affecting migrants to receive occupational disease health education. (See table 4)

\section{Logistic Regression Model}

The finding indicates that all of the full models were able to distinguish between migrants with receiving health education and those without receiving health education, and all predictors were statistically significant at the 0.000 level (model $\nabla, \chi 2=186.467, P=0.000 ;$ Model $\nabla, \chi 2=49.367, P=0.000 ;$ Model $\otimes, \chi 2=$ $39.895, P=0.000$; Model $\nabla, \chi 2=90.941, P=0.000)$. In the model summary, the model $\nabla$ explained between 19.6 per cent (Cox and Snell $R$ square) and 26.3 per

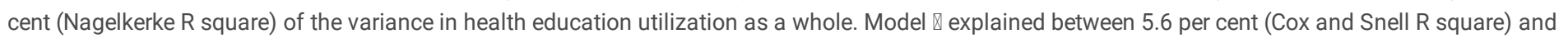
10.7 per cent (Nagelkerke R square) of the variance in communicable disease health education utilization as a whole. Model $\nabla$ explained between 4.6 per cent (Cox and Snell R square) and 9.1 per cent (Nagelkerke R square) of the variance in non-communicable disease health education utilization of migrants as a whole. Model $₫$ explained between 10.1 per cent (Cox and Snell R square) and 17.7 per cent (Nagelkerke R square) of the variance in occupational disease health education utilization as a whole. (See table 5)

Table 6 predicts the determinant factors of health education utilization for migrants (model $₫$ ) by binary logistic regression. Model $₫$ shows that the migrants with $25 \llbracket 34,35 \rrbracket 44,45 \rrbracket 54$, above 55 years old in the past year were at 0.559-times $(\mathrm{OR}=0.559), 0.302$-times $(\mathrm{OR}=0.302), 0.278$-times $(\mathrm{OR}=0.278)$ and 0.232 times $(\mathrm{OR}=0.232)$ lower chances of receiving health education respectively, comparing to $18 \otimes 24$ years old. Migrants with education of university or college and above, high school or secondary, and junior high school were at 4.423-times (OR $=4.423)$, 3.545-times $(\mathrm{OR}=3.545)$, and 2.219-times $(\mathrm{OR}=2.219)$ higher chances of receiving health education respectively in the past year, comparing to migrants with education of primary school or below. Migrants who have at least one child in Beijing $(O R=1.901)$, do exercises $(O R=1.989)$, have chronic disease $(O R=1.565)$ were more likely to receive health education. Plan to reside for a long time in Beijing $(O R=0.674)$, smoking $(O R=0.605)$, were less likely to receive health education. Additionally, the chances of receiving health education were decreased by $43.4 \%$ in poor health status $(O R=0.566)$ and $41.9 \%$ in moderate health status $(O R=0.581)$, comparing to self-evaluated good health status.

Table 7 predicts the determinants of communicable disease, non-communicable disease, and occupational disease health education utilization for migrants (Model $\varangle$, model $\varangle$, and model $\varangle$ ) by binary logistic regression. Model $\nabla$ shows that the chances of receiving communicable disease health education were decreased by $71.0 \%$ in average working time more than 8 hours daily $(O R=0.290)$, comparing to migrants with average working time less than 8 hours daily. Additionally, migrants who do exercises $(O R=2.204)$, acquire health knowledge $(O R=1.954)$ were more likely to receive communicable disease health

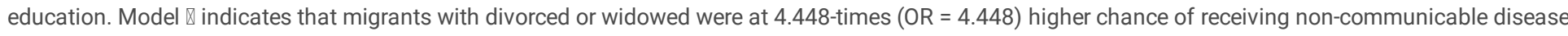


health education, compared to migrants with no married. The chances of receiving non-communicable disease health education were decreased by $74.6 \%$ in average working time more than 8 hours daily $(\mathrm{OR}=0.254)$, comparing to migrants with average working time less than 8 hours daily. Additionally, migrants

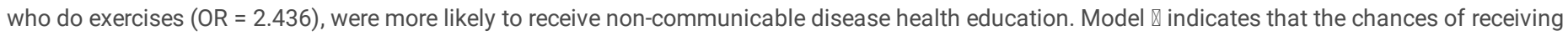
occupational disease health education were decreased by $58.3 \%$ in married $(\mathrm{OR}=0.417)$, and $68.5 \%$ in average working time more than 8 hours daily $(\mathrm{OR}=$ $0.315)$, comparing to migrants with unmarried and average working time less than 8 hours daily respectively. Migrants who have formal work (OR $=2.001)$, do exercises $(\mathrm{OR}=1.827)$, were more likely to receive occupational disease health education.

\section{Discussion}

This study attempted to describe and assess the major determinants associated with the health education utilization for migrants in urban-rural connection of Beijing, to better facilitate health education utilization for them.

\section{Utilization and demands of health education}

Previous researches indicated that the advantage of "healthy migrant effect" (first-generation migrants are often healthier with lower overall morbidity and mortality than local-born populations) will diminish dramatically particular in middle age [23, 24], company with demanding work schedules, poor working and resident environment, insufficient health literacy, and negative attitude to the health preventive behaviors. The research also revealed that though many migrants were aware of significances associated with health education, and expressed a desire to gain access to health information that would allow them to take responsible actions for enhancing their own well-being, low utilization rate persisted, which only $46.2 \%$ migrants received health education in the past year. It was not difficult to show in the study, most of the migrants investigated were middle-aged, and they had age-appropriate health education needs, e.g. antenatal, prenatal and postpartum healthcare, aged healthcare. Furthermore, with the evolution of migration model, migrants should take the responsibilities for caring for their child(ren) and parent(s), thus they have relative high demands of child, adolescent, and aged healthcare. It also seems strange that there were low rates of occupational disease health education utilization and demands actually, which are consistent with the previous study in Xi' an that more than $50 \%$ migrants have not received occupational safety and health protection training [25]. Furthermore, there may be a reason to explain the low demands of occupational disease health education among migrants. Different from acute occupational diseases (occupational allergic contact dermatitis, occupational poisoning) that always occur after a relatively brief exposure, the common chronic occupational diseases (pneumoconiosis, musculoskeletal disorders, psychological stress at work, occupational tumors) which occupy the majority of occupational diseases, only occur after prolonged exposure to the relevant hazard [26, 27]. Migrants with low health literacy, instable job, and lacking of a full understanding of occupational hazards, would not pay enough attention to occupational diseases, even if chronic occupational diseases having occurred.

\section{Determination factors of whole health education utilization}

The rate of health education utilization was higher in the groups of 18 to 24 and 25 to 34 years old, particular in the first age group, than other three age groups. The result was similar to a previous China-based study that migrants in the group of 25 to 34 years old have higher rate of health education utilization than other age groups, but the rate of migrants in age group of 18 to 24 years old was opposite. There might be two factors account for the differences. Firstly, with higher education level, besides relatively stable working condition, the new-generation migrants who birth after 1980, had better health literacy and could acquire reliable health information derived from a wide range of ways, compared to the old-generation migrants [28]. Meanwhile, this research also indicated that migrants with high education level, do exercises had a higher likelihood of receiving health education. The prevalence of health literacy was related to health knowledge, health decisions, health behaviors and health outcomes of the population [29-31]. On the contrary, low education levels, accompanied by low literacy skills and health awareness, were said to create difficulties and barriers in understanding complex health-related information, health practices and outcomes [32]. Secondly, selection bias would be no enough to demonstrate the results due to insufficient sample size of migrants in age group of 18 to 24 years old. In the future, migrants in this age group should be studied in terms of their health education utilization behaviors and influencing factors as a unique group.

\section{Determination factors of three types of health education utilization}

Considering that there were certain gaps between the demands and utilization of three types of health education which implemented for general migrants population investigated, including communicable disease, non-communicable disease and occupational disease for the investigated migrants, our study took emphases to analysis the determinations factors of three types of health education utilization.

For migrants, we observed that both average working time daily of enabling variables and do exercise of health behavior variables contributed significantly to the variances in three types of health education utilization. Migrants who worked more than 8 hours daily and not to do exercises were less likely to use three types of health education than migrants with working time less than 8 hours and do exercises. Put another way, the heavy workloads in the jobs and poor health awareness for migrant workers reduce the opportunity to receive health information. Additionally, consistent with the previous research [33], migrants with formal work have more likely to receive occupational disease health education than employment status of informal work. Worldwide, the patterns of employment for migrants are similar, no matter in the developing countries or the developed countries. Migrant workers are overwhelmingly employed in 3-D jobs (dirty, dangerous, and degrading), e.g., the service sector, production, construction and maintenance, transportation that report have more health-related risks compared with other industries [34-36]. In accordance with state regulations, employers have the responsibility to educate their workers to protect from specific occupational hazards by providing regular training, and inform the workers have to abide strictly by work safety rules. Nevertheless, migrants who worked in small- and medium-sized enterprises have more risks due to the deficiency of occupational disease health education and supervision than largesized enterprises [37]. Meanwhile, in the informal and temporary working status, long working time and situational stress diminish the demands of acquiring health information especially on occupational disease for migrant workers. 
With the development of information technology (IT), technologies such as smartphones and internet access have become an integral part of our lives, and these are widely used in health information research. The report of "internet adoption, social media usage, and smartphone ownership rates in 37 countries across the world in 2017 " from Pew research center revealed that the rates of internet use, smartphone ownership and social media use were $71 \%, 68 \%$ and $60 \%$ respectively in China [38]. Different from traditional text-based health education tools, including brochures, leaflet, newspaper, web-based social media tools offer a convenient and effective method of delivering health information [39]. Using the WeChat application as an example, as a free instant messaging application for smartphones, it plays an important part in modern lifestyles. WeChat can serve on a bridge using IT technology and frequent multimedia messages to provide health support and management through the communication and propagation of voice, text, pictures, and videos over great distances [40]. Information related to the prevention and treatment of various diseases can be acquired and requested at any time via such applications [41, 42]. The increased widespread of mobile phones into China's communities provides a platform for delivering health education on mobile platforms. As in our study, $58.2 \%$ migrants want to acquire health information via the internet. Therefore, mHealth interventions strategies have enormous potential to be used as an educational tool for behavioral change to further control the spread of epidemics, development of the chronic disease for migrants.

\section{Limitations}

The study has several limitations. Firstly, cross-sectional survey cannot be determined the time-effect and causality accurately, compared with the cohort study. Secondly, recall biases on self-report might underestimated the information on health education utilization. Thirdly, health education utilization was measured as a dichotomous variable (the receive or non-receive of health education), rather than measured the receive intensity of health education. Finally, although the questionnaire was designed according to the previous theories and experience, several significant potential determination factors may not be considered in the model, such as community resource factors. Future research is needed to explain the dynamic and cyclical causal relationships of Anderson's health service utilization model by identifying more variables.

\section{Conclusion}

The findings of the survey contribute to our understanding of the health education utilization and determination factors, and demands of health education among Chinese migrants. There were certain gaps between the needs and utilization in different types of health education. Compared with the old-generation migrants, new-generation migrants had higher rate of health education utilization. Additionally, average working time daily of enabling variables and do exercise of health behavior variables in the Anderson health service utilization model, was a dominant predictor of three types diseases of health education utilization, including CDs, NCDs and occupational diseases. Many migrants desired to access health education information from internet. In the next step, we should focus special attention on the health education utilization for heavy workload and low education level migrants.

The findings of this research would be useful for establishing basic public health service network. It also suggests that policy makers should take feasible policies and measures to overcoming obstacles and break down barriers for migrants, including fully implement of policies, using multiple channels to provide health information, and carry out health education intervention strategies, to ensure easy and equitable access to health education. In the future, more comprehensive studies should be carried out to evaluate the efficiency of health intervention strategies to improve the acquisition and utilization of basic public health services for migrants.

\section{Abbreviations}

SARS: Severe Acute Respiratory Syndrome CD: communicable disease NCD: chronic non-communicable disease RMB: Renminbi CHS/s: community health service institutions IT: information technology PEN: predisposing, enabling, and need variances

\section{Declarations}

\section{Ethics approval and consent to participate}

It was approved by the Ethical Committee of Capital Medical University, Beijing, China. Data were obtained from a 2016 cross-sectional survey in urban-rural connection districts of Beijing. Written informed consent was obtained from each participant involved in this study. For participants under the age of eighteen, written informed consents were obtained from their guardians. All participants' information was kept confidential and tracked anonymously with an identification number only.

\section{Consent for publication}

Not applicable.

\section{Availability of data and materials}

The datasets generated and/or analyzed during the current study are available from the corresponding author on reasonable request.

\section{Competing interests}


The authors declare that they have no competing interests.

\section{Funding}

The study was undertaken as a part of Beijing Philosophy and Social Science Planning Project (15SHC035), which is a population-based cross sectional survey on risk factors of health status for migrants. Apart from inputs on overall progress of this research, as funding body, the funders had no role in the design, collection, analysis, interpretation of data, or writing of the manuscript related to this study.

\section{Authors' contributions}

SS drafted the manuscript and acquired data. SS and HRZ acquired, analyzed, and interpreted the data. JYXX and XLC analyzed the data. YLZ revised the manuscript. JD conceived the study and design and revised the manuscript. All authors read and approved the final manuscript.

\section{Acknowledgements}

To all the primary care workers who participated in this research, the authors convey their sincere thanks and respect for their contribution and sharing of experiences.

\section{Publisher's Note}

Springer Nature remains neutral with regard to jurisdictional claims in published maps and institutional affiliations.

\section{References}

[1] Floating Population Services and Management Division of the National Population and Family Planning Commission. Report on China's migrant population development 2017. China Population Publishing House; 2017. p.6

[2] Salazar MA, Hu X. Health and lifestyle changes among migrant workers in China: implication for the healthy migrant effect. Lancet Diabetes Endocrinol. $2016 ; 4(2): 89-90$.

[3] Song X, Zou G, Chen W, Han S, Zou X, Ling L. Health service utilisation of rural-to-urban migrants in Guangzhou, China: does employment status matter? Trop Med Int Health. 2017; 22(1): 82-91.

[4] Oyebode O, Pape UJ, Laverty AA, Lee JT, Bhan N, Millett C. Rural, urban and migrant differences in non-communicable disease risk-factors in middle income countries: a cross-sectional study of WHO-SAGE data. PLoS One. 2015; 10(4): e0122747.

[5] Bele S, Jiang W, Lu H, You H, Fan H, Huang L, et al. Population aging and migrant workers: bottlenecks in tuberculosis control in rural China. PLoS One. 2014; 3; 9(2): e88290.

[6] Qin L, Jeng H, Rakue Y, Mizota T. A deficient public health system as a contributing cause of Severe Acute Respiratory Syndrome(SARS) epidemic in mainland China. Southeast Asian J Trop Med Public Health. 2005; 36(1): 213-6.

[7] Zhang J, Lin S, Liang D, Qian Y, Zhang D, Hou Z. Public health services utilization and its determinants among internal migrants in China: Evidence from a nationally representative survey. Int J Environ Res Public Health. 2017; 14(9). pii: E1002.

[8] Chinese Social Sciences Today. China's public health system construction: achievements and shortcomings.

http://ex.cssn.cn/djch/djch_djchhg/houfeidianshinian/201312/t20131216_909022.shtml. Accessed Dec 16, 2013.

[9] The Central People's Government of the People's Republic of China. Views on promoting the gradual equalization of basic public health services. http://www.gov.cn/ztzl/ygzt/content_1661065.htm. Accessed July 22, 2010.

[10] Guo L, Bao Y, Li S, Ma J, Sun W. Quality analysis and policy recommendations on the utilization of community basic public health services in urban and suburban Shanghai from 2009 to 2014. Environ Sci Pollut Res Int. 2018; 25(28): 28206-15.

[11] Shi Y, Ji Y, Sun J, Wang Y, Sun X, Li C, et al. Lack of health risk awareness in low-income Chinese youth migrants: assessment and associated factors. Environ Health Prev Med. 2012; 17(5): 385-93.

[12] Wang W, Wei C, Buchholz ME, Martin MC, Smith BD, Huang ZJ, et al. Prevalence and risks for sexually transmitted infections among a national sample of migrants versus non-migrants in China. Int J STD AIDS. 2010; 21(6): 410-5.

[13] Zhang L1, Chow EP, Jahn HJ, Kraemer A, Wilson DP. High HIV prevalence and risk of infection among rural-to-urban migrants in various migration stages in China: a systematic review and meta-analysis. Sex Transm Dis. 2013; 40(2): 136-47. 
[14] Floating Population Services and Management Division of the National Population and Family Planning Commission. Report on China's migrant population development 2016. China Population Publishing House. 2016:6.

[15] National Health and Family Planning Commission. Guiding Opinions on the basic public health and family planning services for migrant population. http://www.bjdch.gov.cn/n1709178/n2680513/n2680514/c6943436/part/6943446.pdf. Accessed Oct 30, 2014.

[16] Gautam A, Bhatta DN, Aryal UR. Diabetes related health knowledge, attitude and practice among diabetic patients in Nepal. BMC Endocr Disord. 2015; 15: 25 .

[17] Khan SA, Moorthy J, Omar H, Hasan SS. People living with HIV/AIDS (PLWHA) and HIV/AIDS associated oral lesions; a study in Malaysia. BMC Public Health. 2012; 12: 850.

[18] Khortwong P, Kaewkungwal J. Thai Health Education Program for Improving TB Migrant's Compliance. J Med Assoc Thai. 2013; 96(3): 365-73.

[19] Solé-Auró A, Guillén M, Crimmins EM. Health care usage among immigrants and native-born elderly populations in eleven European countries: results from SHARE. Eur J Health Econ. 2012;13(6):741-54.

[20] Xue LPखFan H囚Guo J. Current situation of health education and its influencing factors among migrant population (in Chinese). Chinese Journal of Health Education. 2017; 33(9):771-4, 796.

[21] The sixth national population census. The main data bulletin of the sixth national population census in Beijing (2010).

http://www.stats.gov.cn/tjsj/tjgb/rkpcgb/dfrkpcgb/201202/t20120228_30381.html. Accessed 5 May, 2011.

[22] Anderson JG. Health services utilization: framework and review. Health Serv Res. 1973; 8(3):184-99.

[23] Tarnutzer S, Bopp M. Healthy migrants but unhealthy offspring? A retrospective cohort study among Italians in Switzerland. BMC Public Health. 2012;12:1104.

[24] Zhang L, Liu S, Zhang G, Wu S. Internal migration and the health of the returned population: a nationally representative study of China. BMC Public Health. 2015;15: 719.

[25] Fang XZ®Cao XX『Wang WQ. Investigation of occupational health surveillance among migrant population in Xi'an (in Chinese). Chinese Journal of Health Education. 2015; 31(11):1077-9.

[26] Zhang X, Wang Z, Li T. The current status of occupational health in China. Environ Health Prev Med, 2010; 15(5): 263-70.

[27] Moyce SC, Schenker M. Migrant Workers and Their Occupational Health and Safety. Annu Rev Public Health, 2018; 39(1): 351-65.

[28] National Bureau of Statistics. Monitoring and survey report on migrant workers in 2017.

http://www.stats.gov.cn/tjsj/zxfb/201804/t20180427_1596389.html.

Accessed April 27, 2018.

[29] Watanabe N, Kaneko A, Yamar S, Taleo G, Tanihata T, Lum JK, et al. A prescription for sustaining community engagement in malaria elimination on Aneityum Island, Vanuatu: an application of Health Empowerment Theory. Malar J. 2015; 14: 291.

[30] Al SF, Majumdar SR, Williams B, Robertson S, Johnson JA. Health literacy and health outcomes in diabetes: a systematic review. J Gen Intern Med. 2013; 28(3): 444-52.

[31] Wang KY, Chu NF, Lin SH, Chiang IC, Perng WC, Lai HR. Examining the causal model linking health literacy to health outcomes of asthma patients. J Clin Nurs. 2014; 23: 2031-42.

[32] Al SF, Majumdar SR, Williams B, Robertson S, Johnson JA. Health literacy and health outcomes in diabetes: a systematic review. J Gen Intern Med. 2013; 28: $444-52$.

[33] Hou Z, Lin S, Zhang D. Social capital, neighbourhood characteristics and utilisation of local public health services among domestic migrants in China: a cross-sectional study. BMJ Open. 2017; 7(8):e014224.

[34]Economic News Release. Foreign-born workers: labor force characteristics-2015. https://www.bls.gov/news.release/archives/forbrn_05192016.htm. Accessed May 19, 2016.

[35] Preibisch K, Otero G. Does citizenship status matter in Canadian agriculture? Workplace health and safety for migrant and immigrant laborers. Rural Sociol. 2014; 79(2):174-99.

[36] Cui X, Rockett IR, Yang T, Cao R. Work stress, life stress, and smoking among rural-urban migrant workers in China. BMC Public Health. $2012 ; 12: 979$. 
[37] Xu LJ, Zhou JT, Xiao WC, Zhou Y. Status and Countermeasures of Occupational Hazards in Small and Medium- sized Enterprises (in Chinese). Industrial Safety and Environmental Protection. 2012; 38(4): 82-4.

[38] Internet adoption, social media usage, and smartphone ownership. https://www.marketingcharts.com/digital-104833/attachment/pewresearchcenterglobal-internet-smartphone-social-use-july2018. Accessed June 21, 2018.

[39] Bond SE, Crowther SP, Adhikari S, Chubaty AJ, Yu P, Borchard JP, et al. Design and implementation of a novel web-based E-learning tool for education of health professionals on the antibiotic vancomycin. J Med Internet Res. 2017; 19(3): e93.

[40] Zhang X, Wen D, Liang J, Lei J. How the public uses social media wechat to obtain health information in china: a survey study. BMC Med Inform Decis Mak. 2017; 17(Suppl 2): 66.

[41] Zapata BC, Fernandez-Aleman JL, Idri A, Toval A. Empirical studies on usability of mHealth apps: a systematic literature review. J Med Syst. 2015; 39: 119.

[42] Wiederhold BK. mHealth apps empower individuals. Cyberpsychol Behav Soc Netw. 2015; 18: 429-30.

\section{Tables}

Table 1. The list of variables for empirical analysis.

\begin{tabular}{|c|c|c|c|}
\hline \multirow[t]{6}{*}{ Predisposing } & \multirow[t]{2}{*}{ Demography } & Age & 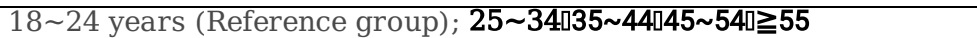 \\
\hline & & Gender & Male (Reference group); Female \\
\hline & \multirow[t]{4}{*}{ Social structure } & Marital status & Unmarried (Reference group); married; divorced/widowed \\
\hline & & Education level & $\begin{array}{l}\text { Primary school or below (Reference group); Junior high school; High } \\
\text { school or secondary; University or college and above }\end{array}$ \\
\hline & & Ethnicity & Han ethnic (Reference group); Minorities \\
\hline & & $\begin{array}{l}\text { "Hukou" registration } \\
\text { system }\end{array}$ & Non-agricultural (Reference group); Agricultural \\
\hline \multirow[t]{8}{*}{ Enabling } & \multirow{8}{*}{$\begin{array}{l}\text { Individual/ } \\
\text { family } \\
\text { resources }\end{array}$} & Time to Beijing & $<1$ years (Reference group); 1 ; 5 ; $\geqq 10$ \\
\hline & & $\begin{array}{l}\text { Plan to reside for a } \\
\text { long time in Beijing }\end{array}$ & No (Reference group); Yes \\
\hline & & $\begin{array}{l}\text { Have at least one child } \\
\text { in Beijing }\end{array}$ & No (Reference group); Yes \\
\hline & & Incoming monthly & $\begin{array}{l}<3000 \text { RMB(Reference group); 3000 4999; 5000 9999; } \\
\geqq 10000\end{array}$ \\
\hline & & Employment status & Formal work (Reference group); Informal work \\
\hline & & Insurance status & Uninsured (Reference group); Insured \\
\hline & & Housing condition & Own house (Reference group); Rent \\
\hline & & $\begin{array}{l}\text { Average working time } \\
\text { daily }\end{array}$ & $<8$ hours (Reference group); 8; >8 \\
\hline \multirow{4}{*}{$\begin{array}{c}\text { Health } \\
\text { behavior }\end{array}$} & \multirow{2}{*}{$\begin{array}{l}\text { Health } \\
\text { promotion } \\
\text { behaviors }\end{array}$} & Do exercise & No (Reference group); Yes \\
\hline & & $\begin{array}{l}\text { Acquire health } \\
\text { knowledge }\end{array}$ & No (Reference group); Yes \\
\hline & \multirow[t]{2}{*}{$\begin{array}{l}\text { Health hazard } \\
\text { behaviors }\end{array}$} & Smoking & No (Reference group); Yes \\
\hline & & Drinking & No (Reference group); Yes \\
\hline \multirow[t]{2}{*}{ Need } & \multicolumn{2}{|c|}{ Having chronic disease } & No (Reference group); Yes \\
\hline & \multicolumn{2}{|c|}{ Self-evaluation general health status } & Good (Reference group); General; Poor \\
\hline
\end{tabular}

Table 2. The types of health education received and hope to receive by migrants.

\begin{tabular}{lll}
\hline Types & Received N (\%)* & Hope to receive N (\%)* \\
\hline Child healthcare & $136(15.8)$ & $404(46.8 \%)$ \\
Occupation disease prevention and therapy & $130(15.1)$ & $279(32.3)$ \\
Antenatal, prenatal and postpartum healthcare & $129(14.9)$ & $307(35.6)$ \\
communicable disease prevention and therapy & $107(12.4)$ & $422(48.9)$ \\
Non-communicable disease prevention and therapy & $96(11.1)$ & $528(61.2)$ \\
Adolescent healthcare & $78(9.0)$ & $328(38.0)$ \\
Aged healthcare & $71(8.2)$ & $409(47.4)$ \\
Menopause healthcare & $56(6.5)$ & $312(36.2)$ \\
Total & $298(34.5)$ & $521(60.4)$ \\
\hline
\end{tabular}


Note: There are overlaps in the number of migrants who received and hope to receive the different types of health education.

Table 3. Information on the whole health education receipt by migrants in different characteristic. 


\begin{tabular}{|c|c|c|c|c|}
\hline \multirow[b]{2}{*}{ Variances } & \multicolumn{4}{|l|}{ Migrants $(n=863)$} \\
\hline & Receive health education N(\%) & Non receive health education $\mathrm{N}(\%)$ & $\chi^{2}$ & $P$ \\
\hline $\begin{array}{l}\text { Predisposing variables } \\
\text { Gender } \\
\text { Male } \\
\text { Female }\end{array}$ & $\begin{array}{l}207(44.6) \\
257(55.4)\end{array}$ & $\begin{array}{l}176(44.1) \\
223(55.9)\end{array}$ & 0.022 & 0.882 \\
\hline $\begin{array}{l}\text { Age } \\
18 \square 24 \\
25 \square 34\end{array}$ & $\begin{array}{l}84(18.1) \\
207(44.6)\end{array}$ & $\begin{array}{l}26(6.5) \\
109(27.3)\end{array}$ & 82.167 & 0.000 \\
\hline $\begin{array}{l}35 \square 44 \\
45 \square 54 \\
\geqq 55 \\
\text { Ethnicity }\end{array}$ & $\begin{array}{l}97(20.9) \\
56(12.1) \\
20(4.3)\end{array}$ & $\begin{array}{l}114(28.6) \\
112(28.1) \\
38(9.5)\end{array}$ & 1.667 & 0.197 \\
\hline Han & $445(95.9)$ & $389(97.5)$ & & \\
\hline $\begin{array}{l}\text { Minority } \\
\text { "Hukoü" registration system } \\
\text { Non-agricultural } \\
\text { Agricultural }\end{array}$ & $\begin{array}{l}19(4.1) \\
163(35.1) \\
301(64.9)\end{array}$ & $\begin{array}{l}32(2.5) \\
85(21.3) \\
314(78.7)\end{array}$ & 20.025 & 0.000 \\
\hline $\begin{array}{l}\text { Marital status } \\
\text { Unmarried } \\
\text { Married }\end{array}$ & $\begin{array}{l}123(26.5) \\
334(72.0)\end{array}$ & $\begin{array}{l}44(11.0) \\
346(86.7)\end{array}$ & 33.125 & 0.000 \\
\hline Divorced/Widowed & $7(1.5)$ & $9(2.3)$ & & \\
\hline $\begin{array}{l}\text { Education level } \\
\text { Primary school or below }\end{array}$ & $18(3.9)$ & $64(50.0)$ & 97.200 & 0.000 \\
\hline $\begin{array}{l}\text { Junior high school } \\
\text { High school or secondary } \\
\text { University or college and above }\end{array}$ & $\begin{array}{l}124(26.7) \\
121(26.1) \\
201(43.3)\end{array}$ & $\begin{array}{l}181(45.4) \\
77(19.3) \\
77(19.3)\end{array}$ & & \\
\hline \multicolumn{5}{|l|}{ Enabling variables } \\
\hline $\begin{array}{l}\text { Incoming } \\
<3000 \mathrm{RMB} \\
3000 \square 4999 \\
\mathbf{5 0 0 0} 9999 \\
\geqq 10000\end{array}$ & $\begin{array}{l}93(20.0) \\
174(37.5) \\
154(33.2) \\
43(9.3)\end{array}$ & $\begin{array}{l}98(24.6) \\
147(36.8) \\
130(32.6) \\
24(0.6)\end{array}$ & 4.951 & 0.175 \\
\hline The time resident in Beijing & & & 6.555 & 0.088 \\
\hline$<1$ year & $50(10.8)$ & $32(8.0)$ & & \\
\hline 10 & $83(17.9)$ & $97(24.3)$ & & \\
\hline $5 \square$ & $156(33.6)$ & 132(33.1) & & \\
\hline$\geqq 10$ & 175(37.7) & $138(34.6)$ & & \\
\hline Plan to reside for a long time in Beijing & & & 49.602 & 0.000 \\
\hline No & $128(27.6)$ & 203(50.9) & & \\
\hline Yes & $336(72.4)$ & 196(49.1) & & \\
\hline $\begin{array}{l}\text { Have at least one child in Beijing } \\
\text { No } \\
\text { Yes }\end{array}$ & $\begin{array}{l}309(66.6) \\
155(33.4)\end{array}$ & $\begin{array}{l}330(82.7) \\
69(17.3)\end{array}$ & 28.977 & 0.000 \\
\hline $\begin{array}{l}\text { Employment status } \\
\text { Formal work }\end{array}$ & $227(48.9)$ & $122(30.6)$ & 29.977 & 0.000 \\
\hline Informal work & $237(51.1)$ & $277(69.4)$ & & \\
\hline Housing source & & & 7.529 & 0.006 \\
\hline $\begin{array}{l}\text { Own house } \\
\text { Rent }\end{array}$ & $\begin{array}{l}69(14.9) \\
395(85.1)\end{array}$ & $\begin{array}{l}35(8.8) \\
364(91.2)\end{array}$ & & \\
\hline Insurance & & & 0.407 & 0.523 \\
\hline Uninsured & $18(3.9)$ & $19(4.8)$ & & \\
\hline Insured & $446(96.1)$ & $380(95.2)$ & & \\
\hline Average working time daily & & & 43.817 & 0.000 \\
\hline$<8$ hours & $16(3.4)$ & $15(3.8)$ & & \\
\hline 8 & $264(56.9)$ & $138(34.6)$ & & \\
\hline$>8$ & $187(39.7)$ & $246(61.7)$ & & \\
\hline \multicolumn{5}{|l|}{ Health behavior } \\
\hline \multicolumn{5}{|l|}{ Health promotion behaviors } \\
\hline Do exercises & & & 29.872 & 0.000 \\
\hline No & $226(48.7)$ & $268(67.2)$ & & \\
\hline Yes & $238(51.3)$ & $131(32.8)$ & & \\
\hline Acquire health knowledge & & & 24.476 & 0.000 \\
\hline No & $188(40.5)$ & $229(57.4)$ & & \\
\hline Yes & $276(59.5)$ & $170(42.6)$ & & \\
\hline \multicolumn{5}{|l|}{ Health hazard behaviors } \\
\hline Smoking & & & 13.121 & 0.000 \\
\hline No & $402(86.6)$ & $308(77.2)$ & & \\
\hline
\end{tabular}




\begin{tabular}{llll} 
Yes & $62(13.4)$ & $91(22.8)$ & 0.223 \\
Drinking & & & $349(87.5)$ \\
No & $418(90.1)$ & $50(12.5)$ & \\
Yes & $46(9.9)$ & & \\
Need variables & & $318(79.7)$ & 0.001 \\
Having chronic disease & & $81(20.3)$ & 24.467 \\
No & $373(80.4)$ & 0.000 \\
Yes & $91(19.6)$ & $97(24.3)$ & $176(44.1)$ \\
Self-evaluation general health status & & $126(31.6)$ \\
Good & $128(27.6)$ & $203(43.8)$ & \\
Moderate & $133(28.7)$ & & \\
Poor & & \\
\hline
\end{tabular}

Table 4. Information on the three types of health education receipt by migrants in different characteristic. 


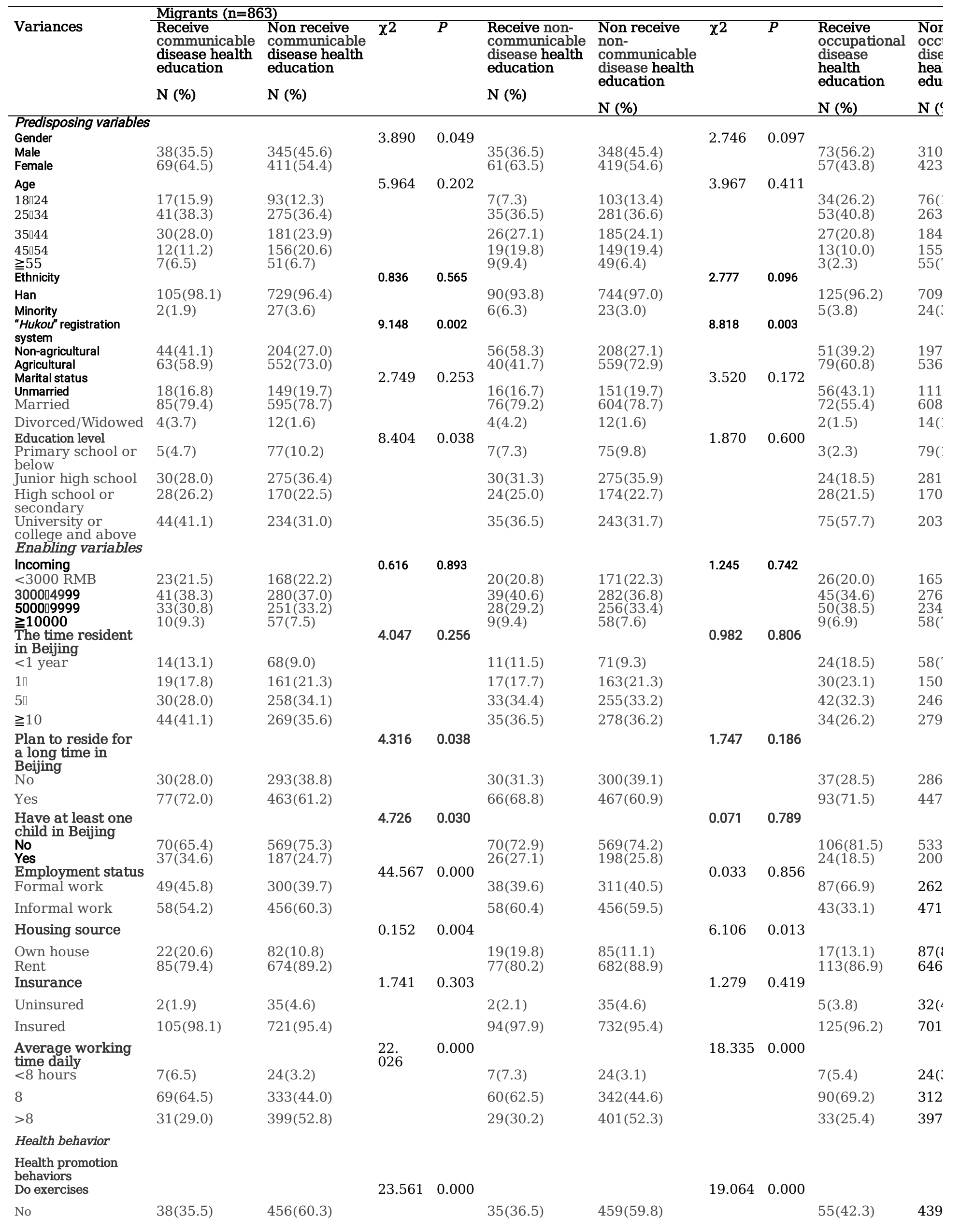




\begin{tabular}{|c|c|c|c|c|c|c|c|c|c|c|}
\hline Yes & $69(64.5)$ & $300(39.7)$ & & & $61(63.5)$ & $308(40.2)$ & & & $75(57.7)$ & 294 \\
\hline Acquire health & & & 15.584 & 0.000 & & & 1.362 & 0.279 & & \\
\hline No & $32(29.9)$ & $385(50.9)$ & & & $41(42.7)$ & $376(49.0)$ & & & 48(36.9) & 369 \\
\hline Yes & $75(70.1)$ & $371(49.1)$ & & & $55(57.3)$ & $391(51.0)$ & & & $82(63.1)$ & 364 \\
\hline \multicolumn{11}{|l|}{$\begin{array}{l}\text { Health hazard } \\
\text { behaviors }\end{array}$} \\
\hline No & $92(86.0)$ & $618(81.7)$ & & & $81(84.4)$ & $629(82.0)$ & & & 104(80.0) & 606 \\
\hline Yes & $15(14.0)$ & $138(18.3)$ & & & $15(15.6)$ & $138(18.0)$ & & & $26(20.0)$ & 127 \\
\hline Drinking & & & 2.804 & 0.094 & & & 2.213 & 0.137 & & \\
\hline No & $90(84.1)$ & $677(89.6)$ & & & $81(84.4)$ & $686(89.4)$ & & & $110(84.6)$ & 657 \\
\hline Yes & $17(15.9)$ & $79(10.4)$ & & & $15(15.6)$ & $81(10.6)$ & & & $20(15.4)$ & 76( \\
\hline \multicolumn{11}{|l|}{ Need variables } \\
\hline $\begin{array}{l}\text { Having chronic } \\
\text { disease }\end{array}$ & & & 0.739 & 0.390 & & & 1.740 & 0.222 & & \\
\hline No & $89(83.2)$ & $602(79.6)$ & & & $72(75.0)$ & $619(80.7)$ & & & 103(79.2) & 588 \\
\hline Yes & 18(16.8) & $154(20.4)$ & & & $24(25.0)$ & 148(19.3) & & & $27(20.8)$ & 145 \\
\hline $\begin{array}{l}\text { Self-evaluation } \\
\text { general health } \\
\text { status }\end{array}$ & & & 1.290 & 0.525 & & & 1.391 & 0.499 & & \\
\hline Good & $32(29.9)$ & $193(25.5)$ & & & $28(29.2)$ & $197(25.7)$ & & & $37(28.5)$ & 188 \\
\hline Moderate & $47(43.9)$ & $332(43.9)$ & & & $44(45.8)$ & $335(43.7)$ & & & $49(37.7)$ & 330 \\
\hline Poor & $28(26.2)$ & $231(30.6)$ & & & $24(25.0)$ & $235(30.6)$ & & & 44(33.8) & 215 \\
\hline
\end{tabular}

Table 5. Model summary of health education utilization of migrants. 


\begin{tabular}{llll}
\hline & -2Log likelihood & Cox and Snell R Square & Nagelkerke R Square \\
\hline $\begin{array}{l}\text { Model } \\
\square^{\mathrm{a}}\end{array}$ & 993.868 & 0.196 & 0.262 \\
$\begin{array}{l}\text { Model } \\
\mathrm{口}^{\mathrm{b}}\end{array}$ & 587.575 & 0.056 & 0.107 \\
$\begin{array}{l}\text { Model } \\
\square^{\mathrm{c}}\end{array}$ & 556.608 & 0.046 & 0.091 \\
$\begin{array}{l}\text { Model } \\
\square^{\mathrm{d}}\end{array}$ & 631.023 & 0.101 & 0.177 \\
\hline
\end{tabular}

Note: Model D: Binary logistic regression analysis of predictors of health education utilization of migrants in the past month.

Model D: Binary logistic regression analysis of predictors of communicable disease health education utilization of migrants in the past month.

Model D: Binary logistic regression analysis of predictors of non-communicable disease health education utilization of migrants in the past month.

Model Q: Binary logistic regression analysis of predictors of occupational disease health education utilization of migrants in the past month.
a: $\chi 2=186.467, P=0.000$
b: $\chi 2=49.367, P=0.000$
c: $\chi 2=39.895, P=0.000$
d: $\chi 2=90.941, \quad P=0.000$

Table 6. Binary logistic regression analysis of predictors of health education utilization of migrants.

\begin{tabular}{|c|c|c|c|}
\hline Variables in the equation & Model I & & \\
\hline & B (SE) & OR[95\%-CI] & $P$-value \\
\hline Predisposing variables & & & \\
\hline & $-0.581(0.274) 4.503$ & $0.559[0.327,0.957]$ & 0.034 \\
\hline & & & \\
\hline & 8) 1 & 9 & \\
\hline$\geqq 55$ & -1.46 & $0.232[0.107$, & 0.000 \\
\hline $\begin{array}{l}\text { Education le } \\
\text { Junior high s }\end{array}$ & 8) 5642 & $2129[1,14$ & \\
\hline High school & 2) 13.70 & 33.545 & 00 \\
\hline University o & $1.487(0.349) 18.09$ & $74.423[2.229,8.774]$ & 0.000 \\
\hline Enabling variables & & & \\
\hline Plan to reside for a long time in Beijing ( $\mathrm{Ref}=$ & & & \\
\hline Yes & $-0.395(0.173) 5.184$ & $0.674[0.479,0.946]$ & 0.023 \\
\hline Yes & $0.642(0.198) 10.561$ & $11901[129028001$ & 0.001 \\
\hline $\begin{array}{l}\text { Health behavior variables } \\
\text { Do exercises (Ref }=\text { No) }\end{array}$ & & & \\
\hline Yes & $0.687(0.160)$ & 1.989[1.454,2.719] & 0.000 \\
\hline $\begin{array}{l}\text { Smoking }(\mathrm{Ref}=\mathrm{No}) \\
\text { Yes }\end{array}$ & $502(0204) 6075$ & $0605[040609021$ & 0.014 \\
\hline $\begin{array}{l}\text { Yes } \\
\text { Need variables } \\
\text { Having chronic disease }(\mathrm{Ref}=\mathrm{No})\end{array}$ & $-0.502(0.204) 6.0 / 5$ & $0.605[0.406,0.902]$ & 0.014 \\
\hline $\begin{array}{l}\text { Yes } \\
\text { Self-evaluation general healt }\end{array}$ & $0.448(0.211) 4.500$ & $1.565[1.035,2.366]$ & 0.034 \\
\hline General & & & \\
\hline & -0.569 & & \\
\hline Constant & $0.096(0.412) 0.054$ & 1.101 & 0.816 \\
\hline
\end{tabular}

Abbreviation: B: Unstandardized regression coefficient. SE: standard error. OR: odds ratio. CI: confidence interval. Ref: reference category.

Model I: Binary logistic regression analysis of predictors of health education receipt by migrants. 
Table 7. Binary logistic regression analysis of predictors of three types health education utilization of migrants.

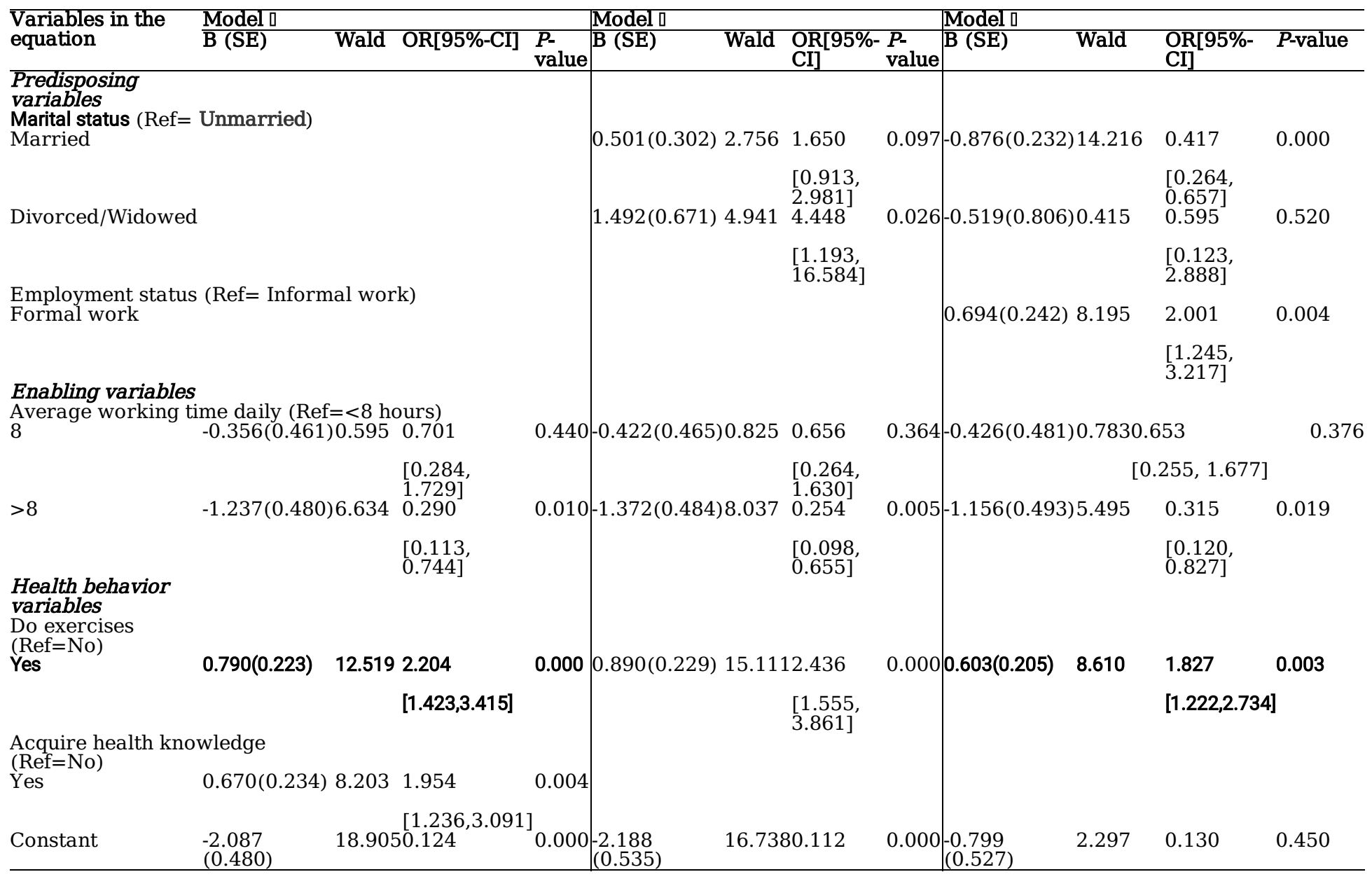

Note: Model D: Binary logistic regression analysis of predictors of communicable disease health education utilization of migrants in the past month.

Model प: Binary logistic regression analysis of predictors of non-communicable disease health education utilization of migrants in the past month.

Model ם: Binary logistic regression analysis of predictors of occupational disease health education utilization of migrants in the past month. 


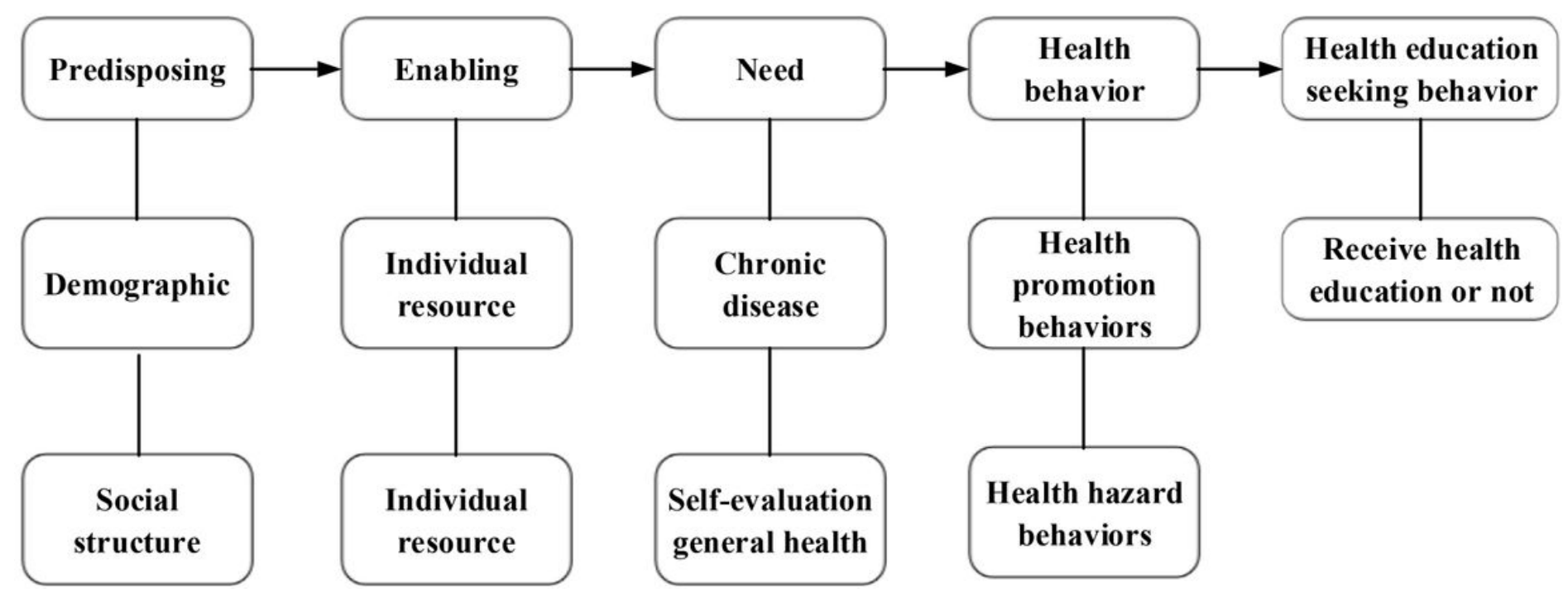

Figure 1

The simplified Anderson health education utilization model. Health education seeking behaviors (seek health service or not) is determined by four dynamics: predisposing (demographic and social structure), enabling (individual and family resources), health behavior variances (health promotion behaviors and health hazard behaviors), and need variances (chronic disease and self-evaluation general health). 